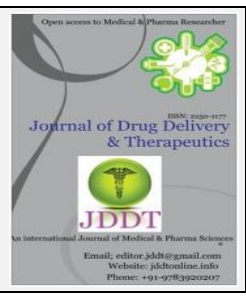

Open $\odot$ Access

Research Article

\title{
Antioxidant properties and subchronic toxicity of the standardized extract of LAMIC, a phytomedicine prototype based on aqueous extracts from trunk bark of Lannea microcarpa Engl and K. Krause
}

\author{
1Belemnaba Lazare*, 2Soubeiga Madi, 1 Ouédraogo Geoffroy G., ${ }^{2}$ Traoré Tata Kadiatou, 1,2Nitiéma Mathieu, ${ }^{1}$ Ilboudo \\ Sylvain, 1,2Belemlilga B. Mohamed, 1,2Compaoré Souleymane, ${ }^{1}$ Sondé/Boly Raïnatou, 1 Ouédraogo Jean Claude Romaric \\ Pingwendé, 1,20uédraogo Salfo, 1Ramdé T. Alphonsine, 10uédraogo Noufou, 2Ouédraogo Moussa and 1 Ouédraogo Sylvin \\ ${ }^{1}$ Research Institute for Health Sciences / National Centre for Scientific and Technological Research (IRSS/CNRST), 03 BP 7047 Ouagadougou \\ 03, Burkina Faso. \\ 2 University Pr Joseph KI-ZERBO, 03 BP 7021 Ouagadougou 03, Burkina Faso.
}

\section{ABSTRACT}

Aims: This study investigated the antioxidant activity and the 90 days subchronic toxicity of the standardized LAMIC phytomedicine prototype based on aqueous extracts from Lannea microcarpa trunk bark.

Methods: Three spectrophotometric methods were used to evaluated the antioxidant activity of LAMIC which were 2,2-Diphenyl-1picrylhydrazyl (DPPH) free radical, 2,2'-azinobis(3-ethylbenzolin-6-sulphonate) (ABTS) radical scavenging assays and ferric reducing antioxidant power (FRAP) assays. For the standardized LAMIC subchronic toxicity study, male and female Wistar rats were used by daily oral administration at doses of 500,1000 and $1500 \mathrm{mg} / \mathrm{kg}$ bw consecutively for 90 days.
\end{abstract}

Results: The LAMIC extract exhibit better inhibitory activity against DPPH radical than ABTS radical with respective $\mathrm{IC}_{50}$ values of $45.38 \pm 3.21$ $\mu \mathrm{g} / \mathrm{mL}$ and $66.45 \pm 18.76 \mu \mathrm{g} / \mathrm{mL}$, while FRAP assay exhibit antioxidant activity of $211.34 \pm 15.92 \mathrm{mmol}$ EAA/g.

Subchronic oral administration of LAMIC was well-tolerated at all tested doses. No behavioral and physiological changes and mortality were observed. The LAMIC extract did not present any impact on general hematological parameters and biochemical parameters. Moreover, no significant changes were raised in organ and body weight of treated groups compared to the Control group.

Conclusion: These results support that LAMIC prototype was a valuable source of natural antioxidants and no toxicity was associated to its long terms oral consumption in rats indicating a potential application as a cardiovascular protective formulation.

Keywords: LAMIC-Lannea microcarpa-Standardization-Antioxidant-Subchronic toxicity.

Article Info: Received 06 July 2019; Review Completed 19 August 2019; Accepted 22 August 2019; Available online 15 Sep 2019

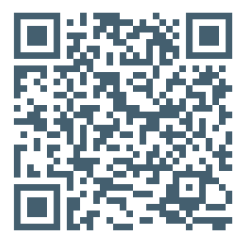

Cite this article as: Belemnaba L, Soubeiga M, Ouédraogo GG., TraoréTK, Nitiéma M, Ilboudo S, Belemlilga BM, Compaoré S, Sondé/Boly R, Ouédraogo J.C.R.P.., Ouédraogo S, Ramdé TA, Ouédraogo N, Ouédraogo M, Ouédraogo $S$, Antioxidant properties and subchronic toxicity of the standardized extract of LAMIC, a phytomedicine prototype based on aqueous extracts from trunk bark of Lannea microcarpa Engl and K. Krause, Journal of Drug Delivery and Therapeutics. 2019; 9(5):1-8 http://dx.doi.org/10.22270/jddt.v9i5.3285

*Address for Correspondence: Lazare Belemnaba, Research Institute for Health Sciences (IRSS), Department of Medicine and Traditional Pharmacopeia (MEPHATRA/Ph), National Centre for Scientific and Technological Research (CNRST), 03 BP 7047 Ouagadougou 03, Burkina Faso

\section{INTRODUCTION}

According to World Health Organization, more than $80 \%$ of rural populations living in developing countries depend on traditional medicine for the management of priority pathologies. Indeed, the majority of these populations is poor and the management of diseases is expensive in modern medicine hence a renewed interest in medicine and traditional pharmacopoeia. This is the case of high blood pressure still called "silent killer" who is treated for life and whose conventional drugs are very expensive. This pathology is constantly increasing among African populations like other developed countries. The estimate of the total number of adults with hypertension in 2000 was
972 million, of which 333 million in economically strong countries compared to 639 million in developing countries. By 2025, these numbers will rise to $60 \%$ for 1.56 billion hypertensive patients 1 . Thus, the medium and long-term management of this pathology rightly calls for an intensification of the research / development of new drugs, more accessible, cheaper with very few side effects and based on the plants or recipes used traditionally. It is in this context that much research has been undertake to develop phytomedicine for the management of priority pathologies including arterial hypertension, diabetes, inflammatory diseases, etc. In Burkina Faso, the Institute for Research in Health Sciences has developed a standardized phytomedicine prototype called LAMIC, formulated from a 
plant extract called Lannea microcarpa Engl. and K. Krause 2. In traditional medicine, this species is widely used in Burkina Faso to treat various pathologies including hypertension.

Previous studies have shown that extracts of Lannea microcarpa showed no in vitro cytotoxic effect on cell viability. In vivo, no anti-inflammatory (cottonseed oil) or pro-inflammatory effects were detected 3 . In addition, antioxidant activities have already been demonstrated in fruit extracts of the plant 4 . In vitro, the vasodilation effect of the aqueous extract of the trunk bark of Lannea microcarpa on the vascular smooth muscle has also been investigated 5 . Another study has shown that extracts from Lannea microcarpa have diuretic properties and are cyclic nucleotides phosphodiesterase inhibitors. Above all, studies have classified the aqueous extract of this plant as moderately toxic, while an investigation of the oral subacute toxicity of Lannea microcarpa extract for 28-day showed no toxicity in animals 6 . Others authors have also show no toxicity effect revealed in acute and subacute oral toxicity study using an aqueous extract of Lannea microcarpa stem bark 7. Chemically, bark of trunk from Lannea microcarpa has highlighted the presence of sterols, triterpenes, anthracenosides, steroidal and triterpenic glycosides, coumarin derivatives, saponosides, reducing compounds, anthocyanin and phenolic compounds (tannins) 3,5,8.

However, no study to date has been undertaken to verify that the LAMIC phytomedicine prototype after formulation has retained its potential biological effects and would also be safe for its possible use in humans.

It is in this perspective that the present work was undertaken to explore the antioxidant activity and subchronic toxicity of this formulation in order to provide scientific evidence in favor of the therapeutic properties and safety of use of this phytomedicine prototype LAMIC.

\section{MATERIAL AND METHODS}

\section{Reagents}

Trolox; 2,2-diphenyl-1-picrylhydrazyl (DPPH); 2,2'azinobis(3-ethylbenzolin-6-sulphonate) (ABTS); Analytical solvents (Ethyl acetate; methanol; chloroform; formic acid; n-hexane; chloroform; Acetone) were from sigma Aldrich (Steinheim, Germanany); Iron chloride $\left(\mathrm{FeCl}_{3}\right)$ were from Fluka Chemie.

\section{Plant material}

The process of Lannea microcarpa Engl. and K. Krause (Anacardiaceae) trunk barks at the basis of LAMIC were already describes ${ }^{9}$. Briefly, the trunk bark of the plant was harvested in January 2015 on the site of Gampèla, a locality located $18 \mathrm{~km}$ east of Ouagadougou. A sample had been identify by a botanist from the Ecology Laboratory of the University of Ouagadougou and a voucher specimen had been deposited (Voucher number: HNBU 361). The collected samples were air-dried in room without solar light and dust, and were powdered with a mechanical grinder and stocked until used.

\section{Phytomedicine prototype LAMIC}

LAMIC is a phytomedicine prototype formulated at the IRSS and was based on freeze-dried aqueous extract of the trunk bark of Lannea microcarpa Engl and K. Krause 2 .

After the formulation, the macroscopic and organoleptic characteristics, the $\mathrm{pH}$, the total ash content, the residual moisture content (THR), the microbial quality were determined before the availability of the LAMIC phytomedicine prototype used in the studies on the antioxidant and toxicological activity 2 . The antioxidant effect and toxicological investigations were done on the LAMIC prototype.

\section{Experimental animals}

Adult rats (males and females) of Wistar strain aged three to four months (3-4) months weighing on average 173.48 \pm 5.34 g were used. They were provided by the pet shop of the Health Sciences Research Institute (IRSS), where they were fed wheat cake (29\% protein) and running water. They were raised under air conditioning $\left(23-25^{\circ} \mathrm{C}\right)$ in the presence of light $(12 / 24 \mathrm{~h})$ and between $60 \%$ to $75 \%$ humidity. They were used to evaluate the subchronic toxicity of the LAMIC prototype. Male normotensive Wistar rats, $191.70 \pm 24.25 \mathrm{~g}$, from the Research Institute for Health Sciences (Burkina Faso) pet stores were use. Animal experimental procedures were in accordance in accordance with the Declaration of Helsinki for animal experiments 10 .

\section{Antioxidant activity}

The in vitro antioxidant potential of LAMIC phytomedicine prototype were investigated using DPPH, FRAP and ABTS antioxidant methods.

\section{2,2-Diphenyl-1-picrylhydrazyl (DPPH) free radical scavenging assay}

The antioxidant activity of LAMIC was evaluated by the 2,2Diphenyl-1-picrylhydrazyl (DPPH) method previously describe by Kim et al. 11. This method is based on the reduction of the absorbance of the stable free $\mathrm{DPPH}^{\circ}$ at 490 $\mathrm{nm}$, in the presence of an $\mathrm{H}^{\circ}$ radical donor. For that, DPPH (1 $\mathrm{mg} / 25 \mathrm{~mL}$ in absolute methanol) and Trolox (positive control) were used. Then, a series of eight successive dilutions at $1 / 2$ was carried out from a stock solution ( 5 $\mathrm{mg} / \mathrm{mL}$ in ethanol $70 \%$ ) of aqueous extract of LAMIC. The test sample $(20 \mu \mathrm{L})$ was mixed with $200 \mu \mathrm{L}$ of DPPH and then incubate for $30 \mathrm{~min}$ at room temperature. After the incubation period, the absorbance was measured at $490 \mathrm{~nm}$ against a blank, using a spectrophotometer (UV-VIS, Biorad model 680). A DPPH inhibition curve (in percent) was plotted against the concentration of the sample and the DPPH radical scavenging $50 \%$ ( $\mathrm{IC}_{50}$ ) was calculated by the following formula: IC50 $(\%)=($ AbSBlank-AbSExtract $) / A b S$ Blank $\mathrm{x}$ 100

With AbsBlank $=$ Absorbance of the Blank; Absextract $=$ Absorbance of the LAMIC aqueous extract. Then, the Anti Radical Power (ARP) was determined by the formula: ARP = $1 / \mathrm{IC}_{50}$.

\section{Ferric reducing antioxidant power (FRAP) assay}

The Ferric reducing antioxidant power (FRAP) assay was conducted according to Hinneburg et al. 12, in which the ability of the LAMIC aqueous extract to reduce $\mathrm{Fe}^{3+}$ to $\mathrm{Fe}^{2+}$ was determined. LAMIC sample solution $(0.5 \mathrm{~mL}$ of 0.1 $\mathrm{mg} / \mathrm{mL}$ in methanol) was mixed with phosphate buffer $(1.25$ $\mathrm{mL}$ of $0.2 \mathrm{M}, \mathrm{pH} 6.6)$ and potassium hexacyanoferrate $(1.25$ $\mathrm{mL}$ of $1 \%$ in water). After $30 \mathrm{~min}$ of incubation $\left(50^{\circ} \mathrm{C}\right), 1.25$ $\mathrm{mL}$ of trichloroacetic acid (10\% in water) was added and the mixture was centrifuged at $2000 \mathrm{rpm}$ for $10 \mathrm{~min}$. The supernatant $(0.625 \mathrm{~mL})$ was mixed with distilled water $(0.625 \mathrm{~mL})$ and $0.125 \mathrm{~mL}$ of freshly prepared $\mathrm{FeCl}_{3}(1 \%$ in water) and then absorbance was read at $700 \mathrm{~nm}$ with a spectrophotometer (Agilent 8453) equipped with UV-vis ChemStation software. Ascorbic acid was used as standard to plot a calibration curve $\left(\mathrm{R}^{2}=0.99\right)$. Three independent experiments were performed in triplicate. Reducing power was expressed as mmol Ascorbic Acid Equivalent per gram 
(mmol EAA/g) of dry extract according to the following formula: $\mathrm{C}=(\mathrm{c} \times \mathrm{D}) /\left(\mathrm{M} \times \mathrm{C}_{\mathrm{i}}\right)$

With $\quad \mathrm{C}=$ concentration of reducing compounds in mmol $\mathrm{EAA} / \mathrm{g}$ of solids

$$
\begin{aligned}
& \mathrm{c}=\text { concentration of the sample read } \\
& \mathrm{D}=\text { dilution factor of the stock extract solution } \\
& \mathrm{C}_{\mathrm{i}}=\text { concentration of the mother extract solution } \\
& \mathrm{M}=\text { molar mass of Ascorbic acid }(176.1 \mathrm{~g} / \mathrm{mol})
\end{aligned}
$$

\section{ABTS radical scavenging assay}

The free radical inhibition capacity of LAMIC aqueous extract was evaluated according to the method previously described by Re et al. using ABTS 13 .

The ABTS stock solution was prepared in distilled water (19.2 mg/5 mL, m/v), in which $3.312 \mathrm{mg}$ of potassium persulfate was added at $12 \mathrm{~h}-16 \mathrm{~h}$ prior to the experiment and the mixture maintained at ambient temperature (protected from light). After that, $4.5 \mathrm{~mL}$ of the mixture was diluted in $220 \mathrm{~mL}$ of analytical ethanol.

For the test, $20 \mu \mathrm{L}$ of the LAMIC aqueous extract sample (5 $\mathrm{mg} / \mathrm{mL}$ ) in $200 \mu \mathrm{L}$ ABTS solution was used and Trolox was used as positive control. The whole was protected from light at room temperature $\left(25^{\circ} \mathrm{C}\right)$ for 30 minutes and the absorbance were read at $734 \mathrm{~nm}$ using a spectrophotometer (UV-VIS, Biorad model 680). The Trolox Equivalent Antioxidant Capacity (TEAC) was calculated according to the following formula: $\mathrm{TEAC}=\mathrm{ARP} \mathrm{Extract}_{\mathrm{ARP}} / \mathrm{Arolox}_{\text {Tr }}$ Three independent experiments were performed in triplicate.

\section{0-days subchronic toxicity in rats}

Subchronic toxicity has been evaluated according to the guidelines 408 of the Organization for Economic Development and Cooperation 14 . Wistar rats were randomly divided into four (04) groups (10 males and 10 females per group):

- The Control group (Group 1) received vehicle daily oral gavage throughout the course of the study.

- The experiment groups (Group 2-4) were orally administrated LAMIC aqueous extract at doses of 500, 1000 and $1500 \mathrm{mg} / \mathrm{kg}$ body weight respectively, for 90 days.

Body weight and food consumption were recorded weekly while, water intake were daily recorded. At the end of the study, rats were anesthetized with ketamine and blood sample were obtained by cardiac puncture for serum biochemical studies. After blood collection, organs (kidneys, heart, lungs, liver, spleen, testes) were excised, weighed using an analytical balance and macroscopically exanimated.
All organs were stored for further analysis. Blood samples (in the tubes without anticoagulant) were then centrifuged at $3000 \mathrm{rpm}$ for $10 \mathrm{~min}$. The collected sera, stored at $-20^{\circ} \mathrm{C}$, were used for biochemical assay to determine relative parameters of alanine aminotransferase (ALAT), aspartate aminotransferase (AST), calcium, chloride, phosphorus, glucose, total protein, total cholesterol, triglycerides, creatinine and urea.

\section{Statistical analysis}

Statistical analysis was carried out using GraphPad prism 5.00.288 for Windows (GraphPad Software Inc., CA, USA).). For the antioxidant assay, experiment were carried out in triplicate. All data were expressed as Mean \pm Standard Error of the Mean (Mean \pm SEM). The analysis of variance (ANOVA) followed by Bonforroni post-test was performed for the comparison between two experimental groups. The differences were considered significant if $\mathrm{p}<0.05$.

\section{RESULTS}

The antioxidizing activity of the LAMIC extract was assessed by DPPH, ABTS and FRAP assays.

The amount of the LAMIC extract needed to decrease the initial radical DPPH concentration by $50 \%$ is used for the free radical scavenging activity and defined as $\mathrm{IC}_{50}$. To show values directly dependent on antioxidant activity, antiradical power (ARP) was calculated as $1 / \mathrm{IC}_{50}$. The free radical scavenging activity with the LAMIC extract and the Trolox used as positive control were of $45.38 \pm 3.21 \mu \mathrm{g} / \mathrm{mL}$ and $7.17 \pm 0.31 \mu \mathrm{g} / \mathrm{mL}$ respectively (Table I). The ARP values were of 0.02 and 0.14 respectively for the LAMIC extract and the positive control Trolox.

Using ABTS radical scavenging assay, for the determination of antiradical and antioxidant activities, the obtained results were also recorded in Table I and illustrated that the LAMIC extract have an antioxidant activity $(66.45 \pm 18.76 \mu \mathrm{g} / \mathrm{mL})$ even if lower than those of pure Trolox $(3.98 \pm 0.03 \mu \mathrm{g} / \mathrm{mL})$. The results of ABTS radical assays were also presented as Trolox Equivalent Antioxidant Capacity (TEAC) using Trolox as positive reference. The TEAC value of the LAMIC extract was $0.06 \mu \mathrm{g} / \mathrm{mL}$ confirming that it is also active even on ABTS cation and show good antioxidant capacity.

The FRAP assay was used to investigate antioxidant activity of the LAMIC extract which, is based on the capacity of antioxidants to reduce ferric ions $\left(\mathrm{Fe}^{3+}\right)$ to ferrous ions $\left(\mathrm{Fe}^{2+}\right)$. Result was presented in Table I and show that the LAMIC extract has a powerful antioxidant property in the order of $211.34 \pm 15.92 \mathrm{mmol} \mathrm{EAA} / \mathrm{g}$ using the Ascorbic acid used as standard (Table I).

Table I: FRAP (mmol EAA/g), TEAC (Trolox Equivalent Antioxidant Capacity) and IC50 values $(\mu \mathrm{m} / \mathrm{mL}$ ) on the Free radical scavenging capacities of LAMIC activity measured with DPPH and ABTS assay.

\begin{tabular}{lccccc}
\hline Substances & DPPH & \multicolumn{3}{c}{ ABTS } & FRAP \\
\hline & $\mathrm{IC}_{50}(\mu \mathrm{g} / \mathrm{mL})$ & ARP & $\mathrm{IC}_{50}(\mu \mathrm{g} / \mathrm{mL})$ & TEAC $(\mu \mathrm{g} / \mathrm{mL})$ & $(\mathrm{mmol}$ EAA $/ \mathrm{g})$ \\
\hline LAMIC & $45.38 \pm 3.21^{*}$ & 0.02 & $66.45 \pm 18.76^{*}$ & 0.06 & $211.34 \pm 15.92$ \\
Trolox & $7.17 \pm 0.31$ & 0.14 & $3.98 \pm 0.03$ & $\cdots$ & $\cdots$ \\
\hline
\end{tabular}

With ABTS : acide 2, 2'- azino bis-(3-ethylbenzothiazoline-6-sulfonique); ARP: anti radical power; DPPH : 2,2Diphenylpicrylhydrazine; TEAC: Trolox Equivalent Antioxidant Capacity ; FRAP: Ferric Reducing Antioxidant Power. Each value represent the mean $\pm S E M$ of three independent experiments $\left(n=3\right.$ in triplicate; $\left.{ }^{*} p<0.001\right)$.

\section{Subchronic toxicity in rats}

\section{Effect of LAMIC on rats body weight gain}

The figure 1 shows the body weight of rats before and during the LAMIC extract subchronic treatment. After observing body weight changes for 90 days, animals in both controls groups and the LAMIC extract treated groups at doses of 500, 1000 and $2000 \mathrm{mg} / \mathrm{kg} / \mathrm{bw}$ showed increase in their body weights at a normal rate, indicating that the LAMIC extract had no significant effect on body weight 
changes compared to the normal control groups. No death or hazardous signs of toxicity were recorded in the both sex of rats during period of experiment after oral treatment with
LAMIC. Moreover, no abnormal change in the ingestive behavior and sensory nervous system responses were noted through the entire treatment.
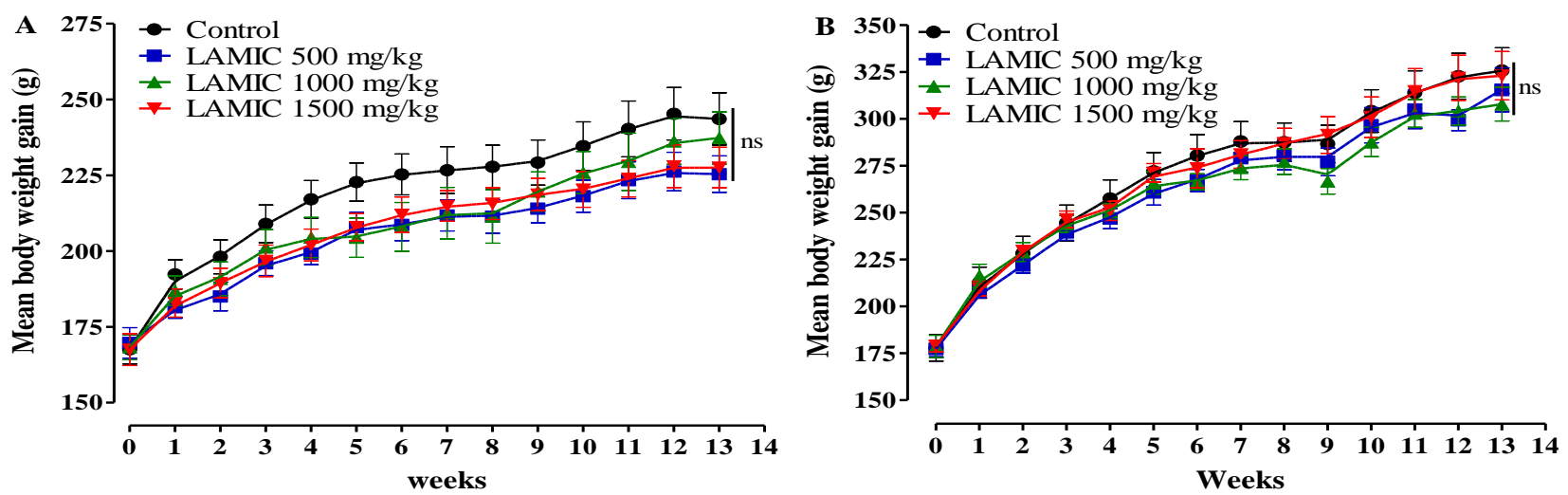

Figure 1: Mean body weight gain in female (A) and male (B) rats with the LAMIC extract treatment for 90 days. Data are presented as Mean $\pm \operatorname{SEM}(n=10$ males or $n=10$ females for each group; $p<0.05$ is considered as statistically significant compared to the Control group).

\section{Effect of LAMIC on food consumption}

Results on food consumption are presented in Table II. During the recovery period, there was no significant change in food intake in all groups of both sex at all the doses of
LAMIC tested as compared to the Control group. A slightly decrease in food consumption was observed in both treated male and female but without significant difference compared to the normal group.

Table II: Mean food consumption by rat administrated LAMIC for 90 days (A: female group; B: male group). Data were expressed as Mean \pm S.E.M.; $\mathrm{p}<0.05$ versus Control group is considered as a significant difference.

\begin{tabular}{|c|c|c|c|c|}
\hline \multirow{2}{*}{$\begin{array}{l}\text { A: Female } \\
\text { Weeks }\end{array}$} & \multirow[b]{2}{*}{ Control } & \multicolumn{3}{|c|}{ LAMIC (mg/kg/bw) } \\
\hline & & 500 & 1000 & 1500 \\
\hline S1 & 19.00 & 15.14 & 17.84 & 16.16 \\
\hline S2 & 18.91 & 16.34 & 16.31 & 16.70 \\
\hline S3 & 17.76 & 15.99 & 15.77 & 16.21 \\
\hline S4 & 17.87 & 15.37 & 15.93 & 15.83 \\
\hline S5 & 16.03 & 14.35 & 14.10 & 14.81 \\
\hline S6 & 16.61 & 18.70 & 14.90 & 15.76 \\
\hline S7 & 16.16 & 16.20 & 15.16 & 16.33 \\
\hline S8 & 14.44 & 13.54 & 15.04 & 14.13 \\
\hline S9 & 15.46 & 14.05 & 17.19 & 15.84 \\
\hline S10 & 17.00 & 15.30 & 16.17 & 15.76 \\
\hline S11 & 16.36 & 14.70 & 15.41 & 15.33 \\
\hline S12 & 17.01 & 15.13 & 16.24 & 14.68 \\
\hline S13 & 12.36 & 11.09 & 12.19 & 11.35 \\
\hline \multirow{2}{*}{$\begin{array}{r}\text { B : Male } \\
\text { Weeks }\end{array}$} & & \multicolumn{3}{|c|}{ LAMIC (mg/kg/bw) } \\
\hline & Control & 500 & 1000 & 1500 \\
\hline S1 & 22.30 & 18.99 & 21.36 & 19.86 \\
\hline S2 & 23.71 & 18.38 & 19.93 & 20.44 \\
\hline S3 & 22.99 & 16.47 & 19.06 & 18.64 \\
\hline S4 & 24.71 & 17.71 & 17.73 & 18.11 \\
\hline S5 & 23.17 & 17.35 & 17.43 & 18.62 \\
\hline S6 & 22.36 & 19.27 & 18.90 & 18.29 \\
\hline S7 & 23.43 & 19.19 & 17.21 & 18.21 \\
\hline S8 & 18.59 & 16.73 & 16.27 & 17.25 \\
\hline S9 & 19.07 & 16.88 & 15.99 & 19.95 \\
\hline S10 & 19.96 & 19.45 & 18.63 & 19.77 \\
\hline S11 & 20.26 & 18.23 & 19.64 & 22.73 \\
\hline S12 & 21.07 & 20.06 & 19.94 & 20.49 \\
\hline S13 & 16.37 & 14.74 & 14.60 & 15.41 \\
\hline
\end{tabular}

Data were expressed as Mean \pm S.E.M.; $\mathrm{p}<0.05$ versus Control group is considered as a significant difference ( $\mathrm{n}=10 \mathrm{female}$ or 10 male). 


\section{Effect of LAMIC on rat water intake}

Animals food consumption was measured and recorded weekly for each group in all four groups during the 90-day study period and presented in Table III. Results shows that water consumption is very similar for all four groups even the little increase or decrease in values but no significant difference $(p>0.05)$ is obtain compared to the Control group.

Table III: Water intake in Control and LAMIC-treated rats for 90 days.

\begin{tabular}{|c|c|c|c|c|c|}
\hline \multirow[b]{2}{*}{ Weeks } & \multirow[b]{2}{*}{ Sex } & \multirow[b]{2}{*}{ Control } & \multicolumn{3}{|c|}{ Doses $(\mathrm{mg} / \mathrm{kg} / \mathrm{bw})$} \\
\hline & & & 500 & 1000 & 1500 \\
\hline \multirow{2}{*}{ S1 } & $\mathrm{M}$ & $34.50 \pm 2.24$ & $31.64 \pm 2.34$ & $33.86 \pm 2.36$ & $33.64 \pm 6.86$ \\
\hline & $\mathrm{F}$ & $33.50 \pm 2.42$ & $29.43 \pm 4.94$ & $33.93 \pm 5.65$ & $27.21 \pm 3.45$ \\
\hline \multirow{2}{*}{$\mathrm{S} 2$} & $\mathrm{M}$ & $37.57 \pm 2.07$ & $34.43 \pm 2.21$ & $33.86 \pm 3.15$ & $37.57 \pm 3.87$ \\
\hline & $\mathrm{F}$ & $34.50 \pm 2.45$ & $30.14 \pm 3.61$ & $33.64 \pm 3.46$ & $29.79 \pm 3.31$ \\
\hline \multirow{2}{*}{ S3 } & $\mathrm{M}$ & $37.43 \pm 1.84$ & $34.57 \pm 3.28$ & $34.36 \pm 3.15$ & $35.36 \pm 2.76$ \\
\hline & $\mathrm{F}$ & $33.71 \pm 1.41$ & $30.64 \pm 3.01$ & $32.71 \pm 1.65$ & $29.52 \pm 1.80$ \\
\hline \multirow{2}{*}{ S4 } & $\mathrm{M}$ & $37.14 \pm 1.41$ & $34.94 \pm 2.32$ & $33.29 \pm 1.73$ & $34.14 \pm 1.52$ \\
\hline & $\mathrm{F}$ & $36.14 \pm 1.44$ & $27.79 \pm 1.87$ & $32.79 \pm 1.68$ & $29.92 \pm 2.39$ \\
\hline \multirow{2}{*}{ S5 } & $\mathrm{M}$ & $41.86 \pm 4.87$ & $41.17 \pm 3.08$ & $37.71 \pm 3.46$ & $38.41 \pm 2.14$ \\
\hline & $\mathrm{F}$ & $34.86 \pm 3.29$ & $33.10 \pm 3.30$ & $32.79 \pm 4.30$ & $32.22 \pm 3.08$ \\
\hline \multirow{2}{*}{ S6 } & $\mathrm{M}$ & $42.29 \pm 4.89$ & $41.10 \pm 4.49$ & $36.57 \pm 5.75$ & $36.67 \pm 3.22$ \\
\hline & $\mathrm{F}$ & $34.36 \pm 4.26$ & $31.35 \pm 1.78$ & $33.64 \pm 2.54$ & $29.52 \pm 2.39$ \\
\hline \multirow{2}{*}{ S7 } & $\mathrm{M}$ & $41.07 \pm 3.47$ & $47.34 \pm 3.11$ & $38.57 \pm 1.67$ & $34.91 \pm 3.69$ \\
\hline & $\mathrm{F}$ & $34.36 \pm 2.73$ & $31.70 \pm 1.24$ & $33.29 \pm 2.61$ & $31.19 \pm 2.04$ \\
\hline \multirow{2}{*}{ S8 } & $\mathrm{M}$ & $49.64 \pm 5.02$ & $54.61 \pm 4.73$ & $42.21 \pm 3.16$ & $42.50 \pm 3.39$ \\
\hline & $\mathrm{F}$ & $35.57 \pm 2.46$ & $32.68 \pm 4.25$ & $36.50 \pm 3.37$ & $31.75 \pm 2.67$ \\
\hline \multirow{2}{*}{ S9 } & $\mathrm{M}$ & $53.93 \pm 1.37$ & $38.12 \pm 3.16$ & $50.07 \pm 4.14$ & $45.71 \pm 3.09$ \\
\hline & $\mathrm{F}$ & $35.50 \pm 3.37$ & $32.41 \pm 4.98$ & $41.86 \pm 4.96$ & $33.02 \pm 3.09$ \\
\hline \multirow{2}{*}{$\mathrm{S} 10$} & $\mathrm{M}$ & $36.21 \pm 2.32$ & $32.99 \pm 3.02$ & $33.57 \pm 2.57$ & $31.39 \pm 5.71$ \\
\hline & $\mathrm{F}$ & $31.43 \pm 2.56$ & $29.29 \pm 2.46$ & $31.43 \pm 2.44$ & $29.92 \pm 3.18$ \\
\hline \multirow{2}{*}{$\mathrm{S} 11$} & M & $34.14 \pm 1.25$ & $38.70 \pm 4.75$ & $32.43 \pm 1.72$ & $34.02 \pm 1.65$ \\
\hline & $\mathrm{F}$ & $29.93 \pm 2.01$ & $26.25 \pm 2.58$ & $29.44 \pm 3.88$ & $25.32 \pm 2.68$ \\
\hline \multirow{2}{*}{$\mathrm{S} 12$} & $\mathrm{M}$ & $37.50 \pm 1.61$ & $35.55 \pm 2.41$ & $32.36 \pm 2.97$ & $34.98 \pm 2.51$ \\
\hline & $\mathrm{F}$ & $33.36 \pm 2.48$ & $28.39 \pm 3.18$ & $33.25 \pm 4.77$ & $28.17 \pm 3.07$ \\
\hline \multirow{2}{*}{$\mathrm{S} 13$} & $\mathrm{M}$ & $36.30 \pm 1.04$ & $39.10 \pm 2.66$ & $33.44 \pm 2.06$ & $34.71 \pm 2.56$ \\
\hline & $\mathrm{F}$ & $31.00 \pm 2.26$ & $26.50 \pm 4.21$ & $31.11 \pm 3.22$ & $27.67 \pm 3.23$ \\
\hline
\end{tabular}

All data were expressed as Mean \pm S.E.M.; $\mathrm{p}<0.05$ versus Control group is considered as a significant difference $(\mathrm{n}=10 \mathrm{female}$ or 10 male).

\section{Effect of LAMIC on rat relative organ weights}

Table IV shows the relative organ weights of Control and LAMIC treated rats from subchronic toxicity study. The results that the heart, liver, lung, spleen, gonads (testes or ovaries) of the animals in experimental groups ranging from
500,1000 and $1500 \mathrm{mg} / \mathrm{kg} / \mathrm{bw}$ had no significant difference ( $p>0.05)$ compared with their respective control groups. Moreother, in the macroscopic analysis of the different organs, there were not alterations in the relative weight or in the morphology that could be attributed to the LAMIC treatment.

Table IV: Relative organs weight from Control groups and LAMIC-treated groups after 90 days experiment and autopsy.

\begin{tabular}{lccccc}
\hline \multirow{2}{*}{ Organs } & Sex & Control & $\mathbf{5 0 0}$ & $\mathbf{1 0 0 0}$ & $\mathbf{1 5 0 0}$ \\
\cline { 4 - 6 } \multirow{2}{*}{ Heart } & $\mathrm{M}$ & $0.29 \pm 0.02$ & $0.31 \pm 0.07$ & $0.31 \pm 0.03$ & $0.29 \pm 0.03$ \\
& $\mathrm{~F}$ & $0.32 \pm 0.03$ & $0.32 \pm 0.02$ & $0.30 \pm 0.02$ & $0.35 \pm 0.04$ \\
\hline \multirow{2}{*}{ Liver } & $\mathrm{M}$ & $2.65 \pm 0.26$ & $2.43 \pm 0.48$ & $2.40 \pm 0.11$ & $2.25 \pm 0.05$ \\
& $\mathrm{~F}$ & $2.66 \pm 0.24$ & $2.50 \pm 0.18$ & $2.34 \pm 0.31$ & $2.47 \pm 0.18$ \\
\hline \multirow{2}{*}{ Lung } & $\mathrm{M}$ & $0.51 \pm 0.06$ & $0.51 \pm 0.08$ & $0.53 \pm 0.05$ & $0.52 \pm 0.08$ \\
& $\mathrm{~F}$ & $0.63 \pm 0.14$ & $0.58 \pm 0.06$ & $0.57 \pm 0.04$ & $0.62 \pm 0.07$ \\
\hline \multirow{2}{*}{ Kidneys } & $\mathrm{M}$ & $0.60 \pm 0.03$ & $0.61 \pm 0.11$ & $0.60 \pm 0.04$ & $0.58 \pm 0.03$ \\
& $\mathrm{~F}$ & $0.66 \pm 0.07$ & $0.62 \pm 0.03$ & $0.60 \pm 0.06$ & $0.61 \pm 0.05$ \\
\hline \multirow{2}{*}{ Spleen } & $\mathrm{M}$ & $0.20 \pm 0.05$ & $0.21 \pm 0.03$ & $0.22 \pm 0.04$ & $0.19 \pm 0.02$ \\
& $\mathrm{~F}$ & $0.23 \pm 0.04$ & $0.23 \pm 0.02$ & $0.28 \pm 0.15$ & $0.24 \pm 0.04$ \\
\hline \multirow{2}{*}{ Gonads } & $\mathrm{M}$ & $2.64 \pm 0.60$ & $3.02 \pm 0.39$ & $2.89 \pm 0.38$ & $2.67 \pm 0.24$ \\
& $\mathrm{~F}$ & $0.09 \pm 0.04$ & $0.22 \pm 0.31$ & $0.08 \pm 0.03$ & $0.09 \pm 0.04$ \\
\hline
\end{tabular}

All values are expressed as Mean \pm SEM and $\mathrm{p}<0.05$ is considered as statistically significant compared to the Control group. $(\mathrm{n}=$ 10; male or female for each group). 


\section{Effect of LAMIC on biochemical parameters}

The effect of LAMIC extract subchronic administration on biochemical parameters are presented in Table V. The LAMIC extract had no effect on serum electrolytes $\left(\mathrm{Ca}^{2+}\right.$, $\mathrm{PO}_{4}{ }^{2-}$ and $\mathrm{Cl}^{-}$). In the kidney function parameters, results show that creatinine, total proteins, glucose, did not reveal any significant changes even urea is very slightly increase in LAMIC-treated animals. Furthermore, there was no significant difference in the level of tested liver function enzymes such as, such as ASAT and ALAT even there is a decrease in values of both treated sex compared to their respective untreated groups. However, the decrease in ASAT values were dose-dependent for both sex with exception in female at dose of $1000 \mathrm{mg} / \mathrm{kg}$ bw. The liver parameters such as total cholesterol had no significantly changed in LAMICtreated group; but triglycerides are slightly decrease in male and increase in female treated groups respectively but not significantly different to those of the Control group.

Table V: Serum clinical biochemistry parameters in males and female rats after 90-days LAMIC oral treatment.

\begin{tabular}{|c|c|c|c|c|c|}
\hline \multirow[b]{2}{*}{ Parameters } & \multirow[b]{2}{*}{ Sex } & \multirow[b]{2}{*}{ Control } & \multicolumn{3}{|c|}{ LAMIC (mg/kg/bw) } \\
\hline & & & 500 & 1000 & 1500 \\
\hline \multirow{2}{*}{ Triglycerides (mg/dL) } & $\mathrm{M}$ & $37.68 \pm 18.08$ & $27.21 \pm 07.09$ & $24.45 \pm 5.29$ & $30.97 \pm 5.75$ \\
\hline & $\mathrm{F}$ & $30.60 \pm 10.75$ & $27.94 \pm 06.95$ & $33.99 \pm 6.34$ & $34.66 \pm 32.11$ \\
\hline \multirow{2}{*}{ Total proteins $(\mathrm{g} / \mathrm{L}$ ) } & M & $44.87 \pm 2.61$ & $45.60 \pm 01.87$ & $48.37 \pm 4.56$ & $48.23 \pm 01.33$ \\
\hline & $\mathrm{F}$ & $47.28 \pm 2.56$ & $48.84 \pm 01.70$ & $49.08 \pm 2.87$ & $46.59 \pm 02.45$ \\
\hline \multirow{2}{*}{ Calcium (mmol/L) } & M & $03.04 \pm 0.11$ & $03.01 \pm 0.05$ & $03.03 \pm 0.05$ & $03.05 \pm 0.04$ \\
\hline & $\mathrm{F}$ & $02.97 \pm 0.12$ & $03.03 \pm 0.08$ & $03.05 \pm 0.05$ & $02.97 \pm 0.07$ \\
\hline \multirow{2}{*}{ Chloride (mmol) } & M & $88.80 \pm 1.87$ & $88.20 \pm 01.40$ & $87.75 \pm 1.39$ & $87.71 \pm 0.95$ \\
\hline & $\mathrm{F}$ & $88.40 \pm 1.07$ & $87.63 \pm 0.74$ & $88.63 \pm 1.06$ & $89.00 \pm 01.50$ \\
\hline \multirow{2}{*}{ ASAT (UI/L) } & M & $171.69 \pm 63.01$ & $147.13 \pm 61.32$ & $109.13 \pm 73.57$ & $91.14 \pm 19.42$ \\
\hline & $\mathrm{F}$ & $178.84 \pm 66.62$ & $164.21 \pm 52.16$ & $176.52 \pm 70.80$ & $103.30 \pm 17.19$ \\
\hline \multirow{2}{*}{ ALAT (UI/L) } & M & $62.40 \pm 22.87$ & $53.46 \pm 09.73$ & $43.76 \pm 6.82$ & $49.34 \pm 11.68$ \\
\hline & $\mathrm{F}$ & $39.20 \pm 09.12$ & $35.70 \pm 04.86$ & $38.28 \pm 10.77$ & $31.53 \pm 06.63$ \\
\hline \multirow{2}{*}{ Phosphorus (mmol/L) } & M & $03.54 \pm 01.40$ & $03.07 \pm 0.45$ & $02.71 \pm 0.47$ & $02.69 \pm 0.21$ \\
\hline & $\mathrm{F}$ & $02.51 \pm 0.42$ & $02.48 \pm 0.24$ & $02.90 \pm 0.67$ & $02.41 \pm 0.20$ \\
\hline \multirow{2}{*}{ Glucose (mg/dL) } & M & $87.64 \pm 27.20$ & $101.29 \pm 18.93$ & $101.80 \pm 15.69$ & $115.30 \pm 26.39$ \\
\hline & $\mathrm{F}$ & $85.35 \pm 16.98$ & $78.36 \pm 09.26$ & $79.43 \pm 19.84$ & $88.00 \pm 12.11$ \\
\hline \multirow{2}{*}{ Total Cholesterol (mg/dL) } & M & $53.96 \pm 11.23$ & $53.30 \pm 08.22$ & $48.73 \pm 11.51$ & $44.95 \pm 15.17$ \\
\hline & $\mathrm{F}$ & $48.45 \pm 11.59$ & $49.09 \pm 13.01$ & $48.49 \pm 7.41$ & $43.70 \pm 18.74$ \\
\hline \multirow{2}{*}{ Creatinine $(\mu \mathrm{mol} / \mathrm{L})$} & M & $64.38 \pm 12.20$ & $60.10 \pm 06.20$ & $57.91 \pm 4.41$ & $65.53 \pm 05.45$ \\
\hline & $\mathrm{F}$ & $63.18 \pm 06.27$ & $62.54 \pm 07.23$ & $54.41 \pm 5.17$ & $59.95 \pm 02.83$ \\
\hline \multirow{2}{*}{ Urea $(\mathrm{mg} / \mathrm{dL})$} & M & $50.86 \pm 05.34$ & $53.76 \pm 09.08$ & $44.79 \pm 8.07$ & $54.19 \pm 08.99$ \\
\hline & $\mathrm{F}$ & $48.15 \pm 08.16$ & $50.48 \pm 07.60$ & $53.14 \pm 15.01$ & $53.51 \pm 09.67$ \\
\hline
\end{tabular}

With ASAT = aspartate aminotransferase and ALAT = alanine aminotransferase. All data are expressed as Mean \pm SEM; $p<0.05$ is considered as statistically significant compared to the Control group ( $\mathrm{n}=10$; male or female for each group).

\section{DISCUSSION}

Lannea microcarpa is a plant widely used in Burkina Faso traditional medicine to treat several diseases including hypertension. Previous preclinical studies showed that extracts from this species have vasodilatory effects, antihypertensive properties and are powerful inhibitors of purified phosphodiesterases 5,15 . Others studies also indicate the presence of chemical groups compounds such as steroids, triterpenoids, coumarins, saponins, anthocyanins, tannins etc. in the extracts of Lannea microcarpa trunk barks $5,8,15$. Moreover, previous studies have shown that the acute toxicity of the aqueous extract from Lannea microcarpa trunk bark was of $\mathrm{LD}_{50}=5000 \mathrm{mg} / \mathrm{kg}$ bw, while the 28 days subacute oral toxicity study indicate no mortality observed for doses of 100,500 , and $1000 \mathrm{mg} / \mathrm{kg}$ bw in both sex ${ }^{6}$. In addition, a prototype formulation and the quality control of the plant material were also investigate. This prototype formulation named LAMIC is a phytomedicine prototype based on freeze-dried aqueous extract of the trunk bark of Lannea microcarpa ${ }^{2}$. However, any study to date has been undertake to verify that this phytomedicine prototype after formulation has retained its potential biological effects and might be safe for its possible use in humans. It is the reason why, the present study aims to explore in the first time, the antioxidant activity and the subchronic toxicity of LAMIC prototype formulation in order to provide scientific evidence in favor to the therapeutic properties and the future safety use in the care of hypertension.

Indeed, it is well know that free radical play a crucial role in the pathogenesis of several disease including pulmonary, cancer, rheumatoid, diabetes, cardiovascular diseases, atherosclerosis, hypertension, ischemia/reperfusion injury, etc 16-20. Thus, the present study evaluate the LAMIC antioxidant activity by using three methods that are DPPH radical scavenging activity assay, ABTS radical cation scavenging activity assay and the FRAP assay. Results showed that the LAMIC extract has a good DPPH scavenging activity, even six time lower to that of Trolox with $\mathrm{IC}_{50}$ of $45.38 \pm 3.21 \mu \mathrm{g} / \mathrm{mL}$ and $7.17 \pm 0.31 \mu \mathrm{g} / \mathrm{mL}$ respectively. In contrast, the antioxidant activity obtained by the ABTS assay of this extract was very lower than that of the Trolox ( $66.45 \pm 18.76 \mu \mathrm{g} / \mathrm{mL}$ and $3.98 \pm 0.03 \mu \mathrm{g} / \mathrm{mL}$ respectively). This difference may be explain by the type of antioxidant method assay used. Indeed, several studies indicated that the same substance might give different results for their antioxidant activity depending on the method used 21, 22 . Because the ABTS method evaluates the antioxidant activity of hydrophilic and lipophilic compounds in a substance, the low antioxidant potency of LAMIC phytomedicine may be due to the presence of excipients in the formulation that would inhibit phenolic compounds 23. Indeed, a study 
already showed that an aqueous extract from Lannea microcarpa at the base of the LAMIC formulation has an antiradical activity superior to that of Trolox using ABTS assay 24. Above all, the FRAP method confirmed the reducing power of LAMIC (211.34 $\pm 15.92 \mathrm{mmol} \mathrm{EAA} / \mathrm{g})$ using Ascorbic acid as standard. This reducing power could be attributed to the presence of polyphenolic compounds in LAMIC extract, which are known to have antioxidant activity by their ability to capture free radicals and metal complexation 25-27. The present results are in line with a previous study, which showed that the fruits of Lannea microcarpa have a good antioxidant activity that was correlated with the content in polyphenolic compounds and flavonoids 4 .

The results of the subchronic 90-day oral toxicity study of the LAMIC extract demonstrated that daily oral administration of LAMIC at doses of 500, 1000 and 1500 $\mathrm{mg} / \mathrm{kg} /$ day has no negative influence on the behavior or adverse clinical signs and mortality in all experiment groups.

It is well know that body weight changes or and altered clinical observations weight serve as a sensitive index for the general status of animals 28,29 . The present results suggested that the LAMIC did not affect food and water intake through animals appetite suppression since comparison of food consumption, water intake and rats body weight gain revealed no statistically different between LAMIC-treated rat and controls. However, a very slight decrease in food consumption was observed in treated groups especially in the last week of treatment, although no anorexia was recorded.

Otherwise, the relative organ weights of LAMIC-treated animals after autopsy showed no significant difference from those of the Control group, suggesting that there was no impact on the relative organ weights of the treated rats at any doses of LAMIC investigated.

The alteration in serum biochemical parameters has a higher predictive value for drug toxicity in humans, and is one of the most commonly used diagnostic index in clinical practice 30. In the present subchronic toxicity study, there was no significant change in all the biological parameters of blood serum analyzed in the treated compared to the Control groups. Alanine amino transaminase (ALAT) and aspartate amino transaminase (AST) are widely used as biomarkers for the evaluation of liver damage due to drugs or any other hepatotoxin 31. Their increases are signs of hepatocellular degeneration and necrosis 32, 33. Nevertheless, ALAT and ASAT levels may also rise rapidly in the liver because of several others reasons including hepatitis, cirrhosis, and hepatotoxicity of some drugs 34 . In the present study, the concentration of these two enzymes (ALAT and ASAT) from the LAMIC-treated groups were not significantly different compared to the Control group suggesting no damage in the animals liver. Likewise, decrease in cholesterol and triglyceride levels are proven effective in reducing the incidence of cardiovascular disease $35-38$. In this study, a slight but not significant decrease in total cholesterol and triglyceride compared to the Control group was observed at the dose of $1500 \mathrm{mg} / \mathrm{kg}$ bw suggesting that LAMIC might possessed a protective effect on the cardiovascular system. This result support a recent study in where ethyl acetate fraction from Lannea microcarpa is able to correct angiotensin II-induced hypertension and endothelium dysfunction in an in vivo model ${ }^{15}$. In addition, creatinine is a serum metabolite that the level could but not necessary indicate the physiology of the kidney 39,40 . In this study, no significant change in creatinine values were noticed in LAMIC-treated and Control groups suggesting that this specific organ is not damage. Forevermore, results notice a very slightly increase of urea level in LAMIC-treated animals but not significantly different to those of the Control group confirming that there is no renal impairment. This result could be in line with a previous study in where an aqueous extract from Lannea microcarpa has just a moderate diuretic activity in normotensive rats ${ }^{41}$. Moreover, the LAMIC extract has no effect on serum electrolytes $\left(\mathrm{Ca}^{2+}, \mathrm{PO}_{4}{ }^{2-}\right.$ and $\mathrm{Cl}$ ) just like total proteins and glucose level since most of these differences were very small, not dose-dependent, and/or not found in both sexes. Thus, none of these differences were considered to be toxicological or biological significance.

Above all, the macroscopic examination of vital organs such as the heart, liver, lung, spleen and gonads revealed no treatment-related changes due to administration of the LAMIC prototype phytomedicine. So, the subchronic toxicity that has not revealed harmful effects that affect the target organs of the animals already leads to the conclusion that there is a possibility of safe use of LAMIC.

In summary, the LAMIC has an antioxidant profile without any obvious toxicity in treated groups. It is the first time that the antioxidant properties of the LAMIC prototype phytomedicine from Lannea microcarpa were assessed. Moreover, the present study is the first and the longest duration toxicity study of this prototype to date. There were no biologically or toxicologically significant findings showed in both sexes rats at the doses of 500, 1000 and $1500 \mathrm{mg} / \mathrm{kg}$ bw. Thus, the LAMIC recorded potent antioxidant activity and the lack of toxicity in the present investigation further support the oral safety used of the LAMIC phytomedicine.

\section{ACKNOWLEDGEMENTS}

The "Research Institute for Health Sciences" through the department of Medicine and Traditional Pharmacopeia (MEPHATRA/Ph) supports this work

\section{CONFLICTS OF INTEREST}

THE AUTHORS DECLARE THAT THERE ARE NO COMPETING INTERESTS

\section{FUNDING STATEMENT}

This study has been supported by the "Fonds National de la Recherche et de l'Innovation pour le Développement (FONRID)" from Burkina Faso.

\section{REFERENCES}

1. Kearney PM, Whelton M, Reynolds K, et al. Global burden of hypertension: analysis of worldwide data. Lancet. 2005; 365(9455):217-223.

2. Ouédraogo S. Formulation galénique et contrôle de qualité des extraits des écorces des troncs de Lannea microcarpa Engl. et K. Krause (Anacardiaceae) et de Anogeissus leiocarpus (DC) Guill. et Perr. (Combretaceae) destinés à la prise en charge de l'hypertension artérielle. Diplôme d'Etudes Approfondie en Sciences Pharmaceutiques Spécialité Pharmacie Galénique et Biopharmacie, Université Joseph Ki-Zerbo. 2016:106.

3. Picerno P, Mencherini T, Della Loggia R, et al. An extract of Lannea microcarpa: composition, activity and evaluation of cutaneous irritation in cell cultures and reconstituted human epidermis. J Pharm Pharmacol. 2006;58(7):981-988.

4. Lamien-Meda A, Lamien CE, Compaore MM, et al. Polyphenol content and antioxidant activity of fourteen wild edible fruits from Burkina Faso. Molecules. 2008;13(3):581-594.

5. Ouédraogo $\mathrm{S}$, Belemnaba L, Zague $\mathrm{H}$, et al. Endotheliumindependent vasorelaxation by extract and fractions from Lannea microcarpa Engl. and K. Krause (Anacardiaceae): Possible involvement of phosphodiesterase inhibition. International Journal of Pharmacology and Biological Sciences. 2010:4:9-16. 
6. Nitiéma M, Ilboudo $S$, Belemnaba $L$, et al. Acute and sub-acute toxicity studies of aqueous decoction of the trunk barks from Lannea microcarpa Engl. and K. Krause (anacardiaceae) in rodents. 2018;7(9):30-42.

7. Owusu G, Antwi-Adjei M. Acute and Sub-Acute Oral Toxicity Studies of the Aqueous Extract of Lannea microcarpaStem Bark on Rats. International Journal of Pharmacy and Pharmaceutical Research Human. 2017;9(4):17-30.

8. Nacoulma/Ouédraogo OG. Plantes médicinales et pratiques médicales traditionnelles au Burkina Faso : Cas du plateau central. Thèse Université de Ouagadougou. 1996:p. 242p \& $285 p$.

9. Ouédraogo S, Sombié BC, Ouédraogo JCW, et al. Quality control of trunk's barks of Lannea microcarpa Engl. and K. Krause and Anogeissus leiocarpus (DC) Guill. \& Perr. for the manufacture of phytomedicines for the treatment of hypertension. International Journal of Phytopharmacy. 2017;7(4): 36-41.

10. Salas SP, Russo NM. [Analysis of the main ethical conflicts in the 2008 declaration of Helsinki and the proposed changes in the new version]. Rev Med Chil. 2014;142(4):475-480.

11. Kim KS, Lee S, Lee YS, et al. Anti-oxidant activities of the extracts from the herbs of Artemisia apiacea. J Ethnopharmacol. 2003;85(1):69-72.

12. Hinneburg I, Dorman HJD, Hiltunen R. Antioxidant activities of extracts from selected culinary herbs and spices. Food Chemistry. 2006;97(1):122-129.

13. Re R, Pellegrini N, Proteggente A, et al. Antioxidant activity applying an improved ABTS radical cation decolorization assay. Free Radic Biol Med. 1999;26(9-10):1231-1237.

14. OECD. OECD Guidelines for the Testing of Chemicals. Test No. 408: Repeated Dose 90-day Oral Toxicity Study in Rodents. 25 June $2018 \quad$ https://wwwoecdilibraryorg/docserver/9789264070707-

enpdf?expires $=1563356338 \& i d=i d \&$ accname $=$ guest $\&$ checksum =9A8CB5BD8F3E13D48B15547807FD7AF8. 2018:1-16.

15. Nitiema M, Soleti R, Koffi C, et al. Ethyl Acetate Fraction of Lannea microcarpa Engl. and K. Krause (Anacardiaceae) Trunk Barks Corrects Angiotensin II-Induced Hypertension and Endothelial Dysfunction in Mice. Oxid Med Cell Longev. 2019;2019:9464608.

16. Valko M, Leibfritz D, Moncol J, et al. Free radicals and antioxidants in normal physiological functions and human disease. Int J Biochem Cell Biol. 2007;39(1):44-84.

17. Singh R, Devi S, Gollen R. Role of free radical in atherosclerosis, diabetes and dyslipidaemia: larger-than-life. Diabetes Metab Res Rev. 2015;31(2):113-126.

18. Tu W, Wang H, Li S, et al. The Anti-Inflammatory and AntiOxidant Mechanisms of the Keap1/Nrf2/ARE Signaling Pathway in Chronic Diseases. Aging Dis. 2019;10(3):637-651.

19. Bajic VP, Van Neste C, Obradovic M, et al. Glutathione "Redox Homeostasis" and Its Relation to Cardiovascular Disease. Oxid Med Cell Longev. 2019;2019:5028181.

20. Manonmani G, Bhavapriya V, Kalpana S, et al. Antioxidant activity of Cassia fistula (Linn.) flowers in alloxan induced diabetic rats. J Ethnopharmacol. 2005;97(1):39-42.

21. Huang D, Ou B, Prior RL. The chemistry behind antioxidant capacity assays. J Agric Food Chem. 2005;53(6):1841-1856.

22. Irshad M, Zafaryab M, Singh $M$, et al. Comparative Analysis of the Antioxidant Activity of Cassia fistula Extracts. Int J Med Chem. 2012;2012:157125.

23. Aliakbarlu J, Ghiasi S, Bazargani-Gilani B. Effect of extraction conditions on antioxidant activity of barberry (Berberis vulgaris L.) fruit extracts. Vet Res Forum. 2018;9(4):361-365.
24. Soubeiga M. Étude des propriétés antioxydantes et de la toxicité subchronique du prototype du phytomédicament antihypertenseur LAMIC à base d'extrait aqueux de Lannea microcarpa Engl. et K. Krause (Anacardiaceae). . Doctorat de Pharmmacie, Diplôme d'État. 2018:111p.

25. Dudonne S, Vitrac $X$, Coutiere $P$, et al. Comparative study of antioxidant properties and total phenolic content of 30 plant extracts of industrial interest using DPPH, ABTS, FRAP, SOD, and ORAC assays. J Agric Food Chem. 2009;57(5):1768-1774.

26. Zeghad N, Ahmed E, Belkhiri A, et al. Antioxidant activity of Vitis vinifera, Punica granatum, Citrus aurantium and Opuntia ficus indica fruits cultivated in Algeria. Heliyon. 2019;5(4):e01575.

27. Wen L, Zhao Y, Jiang Y, et al. Identification of a flavonoid Cglycoside as potent antioxidant. Free Radic Biol Med. 2017;110:92-101.

28. El Hilaly J, Israili ZH, Lyoussi B. Acute and chronic toxicological studies of Ajuga iva in experimental animals. J Ethnopharmacol. 2004;91(1):43-50.

29. Michael B, Yano B, Sellers RS, et al. Evaluation of organ weights for rodent and non-rodent toxicity studies: a review of regulatory guidelines and a survey of current practices. Toxicol Pathol. 2007;35(5):742-750.

30. Ojewole JA, Mawoza T, Chiwororo WD, et al. Sclerocarya birrea (A. Rich) Hochst. ['Marula'] (Anacardiaceae): a review of its phytochemistry, pharmacology and toxicology and its ethnomedicinal uses. Phytother Res. 2010;24(5):633-639.

31. Ramaiah SK. Preclinical safety assessment: current gaps, challenges, and approaches in identifying translatable biomarkers of drug-induced liver injury. Clin Lab Med. 2011;31(1):161-172.

32. Gowda S, Desai PB, Hull VV, et al. A review on laboratory liver function tests. Pan Afr Med J. 2009;3:17.

33. Dufour DR, Lott JA, Nolte FS, et al. Diagnosis and monitoring of hepatic injury. II. Recommendations for use of laboratory tests in screening, diagnosis, and monitoring. Clin Chem. 2000;46(12):2050-2068.

34. Rajendran M, Palanivelu S, Panchanatham S. Oral Acute and Subacute Toxicity Studies with Kalpaamruthaa, a Modified Indigenous Preparation, on Rats. 2007;53(4):351-358.

35. Maki KC, Dicklin MR. Do triglyceride-lowering drugs decrease risk of cardiovascular disease? Curr Opin Lipidol. 2017;28(4):374-379.

36. Marz W, Scharnagl H, Gouni-Berthold I, et al. LDL-Cholesterol: Standards of Treatment 2016: A German Perspective. Am J Cardiovasc Drugs. 2016;16(5):323-336.

37. Mogane C, Mokotedi L, Millen AM, et al. Increased systolic blood pressure associated with hypertriglyceridemia in female Sprague Dawley rats. Can J Physiol Pharmacol. 2019.

38. Hernaez A, Soria-Florido MT, Schroder H, et al. Role of HDL function and LDL atherogenicity on cardiovascular risk: A comprehensive examination. PLoS One. 2019;14(6):e0218533.

39. Sottas PE, Kapke GF, Leroux JM. Adaptive Bayesian analysis of serum creatinine as a marker for drug-induced renal impairment in an early-phase clinical trial. Clin Chem. 2012;58(11):1592-1596.

40. Delanaye P, Cavalier E, Pottel H. Serum Creatinine: Not So Simple! Nephron. 2017;136(4):302-308.

41. Nitiéma M, Belemnaba L, Ouédraogo S, et al. Diuretic activity of aqueous decoction extract and ethyl acetate fraction of Lannea microcarpa engl. And k. Krause (anacardiaceae) trunk barks in wistar rats. World Journal of Pharmaceutical Research. 2018;7(19):39-51. 